\title{
The association between nutritional adequacy and 28-day mortality in the critically ill is not modified by their baseline nutritional status and disease severity
}

Charles Chin Han Lew ${ }^{1,2^{*}}$ D, Gabriel Jun Yung Wong ${ }^{2}$, Ka Po Cheung ${ }^{2}$, Robert J. L. Fraser ${ }^{3}$, Ai Ping Chua ${ }^{4}$, Mary Foong Fong Chong ${ }^{5}$ and Michelle Miller ${ }^{1}$

\begin{abstract}
Background: During the initial phase of critical illness, the association between the dose of nutrition support and mortality risk may vary among patients in the intensive care unit (ICU) because the prevalence of malnutrition varies widely (28 to $78 \%$ ), and not all ICU patients are severely ill. Therefore, we hypothesized that a prognostic model that integrates nutritional status and disease severity could accurately predict mortality risk and classify critically ill patients into low- and high-risk groups. Additionally, in critically ill patients placed on exclusive nutritional support (ENS), we hypothesized that their risk categories could modify the association between dose of nutrition support and mortality risk.

Methods: A prognostic model that predicts 28-day mortality was built from a prospective cohort study of 440 patients. The association between dose of nutrition support and mortality risk was evaluated in a subgroup of 252 mechanically ventilated patients via logistic regressions, stratified by low- and high-risk groups, and days of exclusive nutritional support (ENS) [short-term ( $\leq 6$ days) vs. longer-term ( $\geq 7$ days)]. Only the first 6 days of ENS was evaluated for a fair comparison.

Results: The prognostic model demonstrated good discrimination [AUC 0.78 (95\% Cl 0.73-0.82), and a bias-corrected calibration curve suggested fair accuracy. In high-risk patients with short-term ENS ( $\leq 6$ days), each $10 \%$ increase in goal energy and protein intake was associated with an increased adjusted odds (95\% Cl) of 28-day mortality [1.60 (1.192.15) and 1.47 (1.12-1.86), respectively]. In contrast, each 10\% increase in goal protein intake during the first 6 days of ENS in high-risk patients with longer-term ENS ( $\geq 7$ days) was associated with a lower adjusted odds of 28-day mortality [0.75 (0.57-0.99)]. Despite the opposing associations, the mean predicted mortality risks and prevalence of malnutrition between short- and longer-term ENS patients were similar.

Conclusions: Combining baseline nutritional status and disease severity in a prognostic model could accurately predict 28-day mortality. However, the association between the dose of nutrition support during the first 6 days of ENS and 28-day mortality was independent of baseline disease severity and nutritional status.
\end{abstract}

Keywords: NUTRIC, Malnutrition, Mortality, Nutritional support, Critical illness

\footnotetext{
* Correspondence: Charles_lew@nuhs.edu.sg

${ }^{1}$ Nutrition and Dietetics, College of Nursing and Health Sciences, Flinders

University, GPO Box 2100, Adelaide 5001, South Australia

${ }^{2}$ Dietetics and Nutrition Department, Ng Teng Fong General Hospital, 1

Jurong East Street 21, Singapore 609606, Singapore

Full list of author information is available at the end of the article
}

(c) The Author(s). 2019 Open Access This article is distributed under the terms of the Creative Commons Attribution 4.0 International License (http://creativecommons.org/licenses/by/4.0/), which permits unrestricted use, distribution, and reproduction in any medium, provided you give appropriate credit to the original author(s) and the source, provide a link to the Creative Commons license, and indicate if changes were made. The Creative Commons Public Domain Dedication waiver (http://creativecommons.org/publicdomain/zero/1.0/) applies to the data made available in this article, unless otherwise stated. 


\section{Background}

The optimal daily amounts of energy and protein that result in a lower mortality risk in critically ill patients remain uncertain. Heyland et al. [1] proposed that nutritional support may not benefit all patients and consequently developed the Nutrition Risk in Critically Ill score (NUTRIC) to identify patients who would derive the most benefit from nutritional support. This score was subsequently modified to exclude interleukin-6 [modified-NUTRIC (mNUTRIC)] and currently comprises variables such as age, Acute Physiology and Chronic Health Evaluation II score, Sequential Organ Failure Assessment (SOFA) score, length of hospitalization before admission to the intensive care unit (ICU), and number of comorbidities [2]. None of these is nutritional parameters, and it is arguable that the mNUTRIC is a disease severity score. This concept is supported by data from a study by Lew et al. [3] wherein a poor concordance was demonstrated between the mNUTRIC score and the Subjective Global Assessment (SGA)-a validated nutritional assessment tool that has strong mortality prognostic value in critically ill patients $[4,5]$.

The mNUTRIC has a maximum score of 9 , in which the scores 0 to 4 and 5 to 9 are classified as lowmNUTRIC and high-mNUTRIC, respectively. Adequate energy and protein intakes were observed to benefit only high-mNUTRIC patients, with no effect on lowmNUTRIC patients $[2,6,7]$. However, several recent studies have reported conflicting results $[8,9]$. Lew et al. [10] recently validated the mNUTRIC score and observed that the association between mNUTRIC score and 28-day mortality was modified by the timing and dose of nutritional support [10]. Specifically, the study suggested that early high energy and protein intakes were associated with a higher risk of 28-day mortality in high-mNUTRIC patients with short-term nutritional support ( $\leq 6$ days), whereas the inverse was observed in those with longer-term nutritional support ( $\geq 7$ days) [10]. However, the median mNUTRIC scores of these two groups of patients (receiving $\leq 6$ days vs. $\geq 7$ days of nutritional support) at ICU admission were similar, which suggested that the associations between early high energy and protein intakes and 28-day mortality were not modified by baseline disease severity measured by the mNUTRIC score.

It is unclear if the above results reflect the absence of nutritional parameters in the mNUTRIC score because intuitively, malnourished patients would be expected to require more energy and protein to overcome the deleterious effects of critical illness. Lew et al. [3] previously demonstrated that disease severity (measured by the mNUTRIC) and nutritional status (measured by the SGA) independently and in combination can predict mortality [3, 4]. A recent review also recommends simultaneous use of both the mNUTRIC and SGA for complete nutritional evaluation for the critically ill [11]. In light of this, we aimed to develop a new prognostic model, namely the Global Index of Mortality Probability in the Severely ill (GLIMPSE) that combines both mNUTRIC and 7-point SGA to classify patients into low- and high-risk of 28-day mortality (low-GLIMPSE and highGLIMPSE, respectively). In addition, we evaluated whether GLIMPSE categories could modify the association between dose of nutrition support during the first 6 days of exclusive nutritional support (ENS) and 28-day mortality in a single-centre cohort study.

\section{Methods}

\section{Setting and patients}

This was a prospective observational cohort study conducted in the ICU (35 beds) of Ng Teng Fong General Hospital (Singapore). The ICU functions as a closed unit, in which board-certified intensivists and residents provide care for medical, surgical, trauma, cardiac, and neurological patients. The intensivists and nurses were blinded to the objective of the study. Patients are classified as "critically ill" if they are mechanically ventilated and require the support of two or more organ systems. They are downgraded to high dependency status once they are extubated from mechanical ventilation.

To develop GLIMPSE, consecutive patients admitted between August 2015 and October 2016 were screened for enrolment. Patients who were at least 21 years old, had been admitted to the ICU at least $24 \mathrm{~h}$ prior to the screening, and whose nutritional status was established within $48 \mathrm{~h}$ were enrolled. Nutritional status was established by the 7-point SGA, and details have been previously published [4]. Briefly, each 1 point decrease in the 7-point SGA (indicative of a greater degree of malnutrition) was associated with a higher risk of 28-day mortality [4]. Patients who were readmitted to the ICU within the same hospitalization were excluded.

The modifying effects of GLIMPSE categories on the association between the dose of nutrition support during the first 6 days of ENS and 28-day mortality were evaluated in a subgroup of patients. These patients had experienced at least $48 \mathrm{~h}$ of mechanical ventilation and were not pronounced moribund (had medical orders not to resuscitate or had poor prognosis) within $48 \mathrm{~h}$ of ICU admission.

The Domain Specific Review Board approved this study (NHG DSRB Ref: 2014/00878), and informed consent was not required because no attempt was made to change the standard of care in the study.

\section{Data collection}

Patient demographics, admission diagnoses, adequacy of exclusive nutritional support (ENS), and mortality outcome were prospectively recorded in the electronic medical records and retrieved. Since mNUTRIC was not 
part of routine care, it was calculated at the end of the study. Details of the collection of energy and protein intakes via ENS have been previously published [10]. Briefly, adequacy of nutritional support was calculated by dividing the total enteral and/or parenteral nutrition (energy and protein) intake as well as energy provided by propofol and intravenous dextrose by a number of days on ENS and expressed as a percentage of the goals established at ICU admission. This information was recorded from ICU admission to a maximum of 14 days, unless death occurred earlier.

\section{Development of GLIMPSE}

Variables demonstrated to be associated with mortality outcomes in our previous studies were included in GLIMPSE. These comprised the following: (1) disease severity, as measured by the mNUTRIC score [3]; (2) nutritional status, as measured by the 7-point SGA [4]; and (3) cardiopulmonary resuscitation before ICU admission [4]. As there were three predictors, it was estimated that the model required at least 74 events (deaths) in order to ensure model stability [12]. The three predictors were fitted into a multivariable logistic model to predict 28-day mortality. This generated weighted coefficients and a constant that could be used to calculate the predicted mortality risk of patients. More importantly, a logistic model is required for the measurement of internal validity. The internal validity of GLIMPSE was assessed via a bootstrapping technique, in which 1000 re-samples of the entire cohort were created to quantify the discrimination and calibration accuracy of GLIMPSE (R package version 3.5.1. http://CRAN.Rproject.org/package $=$ rms). Discrimination was assessed by using the $C$-index (adjusted for optimism via bootstrapping). Calibration was assessed graphically by preparing a bias-corrected calibration curve and assessing its slope.

\section{Validity of GLIMPSE as an assessment tool for nutritional support}

Lew et al. [10] showed that the associations between early high energy and protein intakes and 28-day mortality in high-mNUTRIC patients with $\leq 6$ days and $\geq 7$ days of ENS were different (increased mortality risk vs. reduced mortality risk, respectively) and the mNUTRIC of these two groups of patients were similar [10]. We adopted the same method used in the earlier study to determine the validity of GLIMPSE in the same subgroup of patients. First, the mortality risks of patients predicted by GLIMPSE were stratified into low- and high-GLIMPSE by using the Youden Index [13]. Second, multivariable logistic regressions were used to determine the associations between energy and protein adequacies and 28-day mortality, stratified by GLIMPSE risk groups and the duration of ENS exposure ( $\leq 6$ days and $\geq 7$ days). To avoid multicollinearity, covariate adjustment was not carried out on variables used to calculate the mNUTRIC score [6]. Statistical analyses were performed using STATA 14.2 (Stata Corp., College Station, TX, USA) and R package (version 3.5.1). For all comparisons, interactions, and associations, a $p$ value $<0.05$ was considered statistically significant.

\section{Results}

There were 440 patients enrolled, and no patients were lost to follow-up (Fig. 1). Mortality at day 28 following ICU admission was $28.0 \%$. Survivors had lower disease severity and were more likely to be well-nourished compared to nonsurvivors (Table 1). Data from a subgroup of 252 patients were used to evaluate the modifying effects of GLIMPSE categories on the association between the dose of energy and protein intakes during the first 6 days of ENS and 28-day mortality. Patients who were excluded had similar characteristics to those included in the validation group apart from a lower SOFA score (mean, 8.1 vs. 9.2, $p<0.001$ ) and a higher number of comorbidities (median, 3 vs. $2, p<0.001$ ). The characteristics of the 252 patients were stratified by their duration of exposure to ENS (short- vs. longer-term ENS). The characteristics of patients with short- and longer-term ENS were similar except for the type of admission, number of comorbidities, and admission diagnosis.

The mean (SD) percentages of energy and protein relative to the requirements for the first 6 days of ICU admission in the validation group were $60.0 \%$ (23.6\%) [15.2 (6.5) kcal/kg] and 55.1\% (24.5\%) [0.64 (0.31) g/ kg], respectively. The actual energy and protein intakes are summarized in Table 2. During the first 6 days of ENS, patients with longer-term ENS had significantly higher energy and protein intakes than those of the patients with short-term ENS ( $p$ value $<0.001$ for both energy and protein). When stratified by nutritional status, the mean percentages of goal energy and protein intakes between the well-nourished and malnourished patients during the first 6 days of ENS (energy, $63.4 \%$ vs. $58.8 \%$, $p=0.172$; protein, $57.4 \%$ vs. $54.2 \%, p=0.368$, respectively) were not signficantly different.

\section{Development of GLIMPSE}

The mNUTRIC score, 7-point SGA, and exposure to cardiopulmonary resuscitation before ICU admission were fitted into a multivariable logistic regression, and they were significantly associated with 28 -day mortality (refer to Additional file 1 for regression parameters). The resultant equation used to calculate the predicted 28 -day mortality risk was $-3.003+($ mNUTRIC $\times 0.477)$ + (7-point SGA $\times-0.166)+($ exposure to cardiopulmonary resuscitation before ICU admission $\times 1.933$ ). 


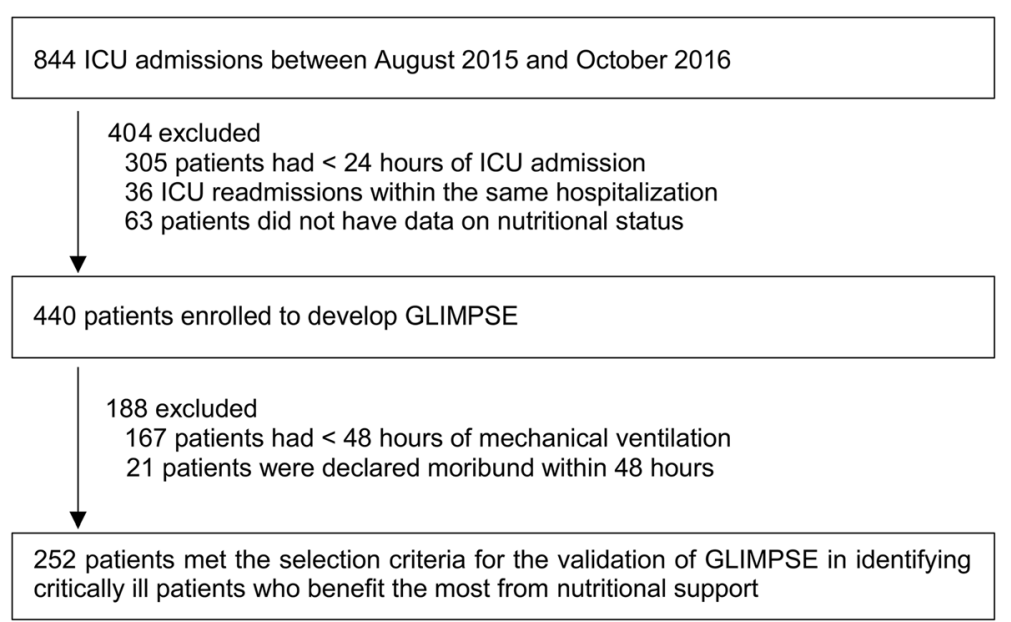

Fig. 1 Enrolment of patients

Internal validation in the model via 1000 bootstrap replicates revealed an adjusted $C$-index and max-rescaled $R^{2}$ of 0.78 (95\% CI $0.73-0.82)$ and 0.30 , respectively. The bias-corrected calibration curve (Fig. 2) suggested overall fair calibration accuracy (slope, 0.98).

\section{Validity of GLIMPSE as an assessment tool for nutritional support}

The optimal cutoff point for defining low- and highGLIMPSE was $20 \%$, and the $C$-index, sensitivity, and specificity were $0.71,87.8 \%$, and $54.6 \%$, respectively. The characteristics of patients classified as low- and highGLIMPSE on the first day of ICU admission were all significantly different except for sex and body mass index (Table 3). However, the mean predicted mortality risks (standard deviation) in patients with short- and longer-term ENS were similar [32.2\% (24.1\%) vs. $27.8 \%$ (21.3\%), respectively, $p=0.122$ ].

Several covariates were not adjusted in the multivariable logistic model. Firstly, location before ICU admission and types of admission were not adjusted although they were significantly associated with mortality at the univariate level (Table 1). When included in a multivariable model (along with GLIMPSE group, adequacy of energy and protein intake, and duration of ENS), these covariates were not significantly associated with mortality (refer to Additional file 1). Secondly, since the duration of ENS was correlated with the duration of mechanical ventilation $(\mathrm{r}=0.82)$ and ICU length of stay $(r=0.67)$, only the duration of ENS was included in the multivariable logistic model [14]. Lastly, time to initiation of enteral feeding was not adjusted because our ICU nutrition policy requires patients to receive enteral nutrition support within $48 \mathrm{~h}$ of ICU admission. Therefore, only 12 patients were not enterally fed within $48 \mathrm{~h}$ of ICU admission. This resulted in an insignificant association with mortality $(p=0.416)$.

In patients with short-term ENS, the associations between energy and protein intakes and 28-day mortality during the first 6 days of ENS were examined in multivariable logistic regression models (Table 4). There were no interactions between the GLIMPSE groups and energy and protein intakes. Generally, there was a positive association between energy and protein intakes and 28-day mortality in both GLIMPSE groups, but it was statistically significant for patients with high-GLIMPSE only.

Similarly, the association between energy and protein intakes and 28-day mortality during the first 6 days of ENS was examined in patients with longer-term ENS (Table 4). There were significant interactions between the GLIMPSE groups and energy and protein intakes. The associations between energy and protein intakes and 28-day mortality in patients with low- and highGLIMPSE appeared to be opposite of each other, but only protein intake was significantly associated with 28 day mortality because each $10 \%$ increase in protein adequacy was associated with a $25 \%$ reduction in the odds of 28-day mortality.

\section{Discussion}

A new prognostic model (GLIMPSE) was developed by combining baseline nutritional status (measured by the 7-point SGA) and disease severity (measured by the mNUTRIC score) to predict 28-day mortality. Internal validation suggested that GLIMPSE had good discrimination and calibration accuracy and was able to identify patients at low and high risk of 28-day mortality. However, the mortality risk established by GLIMPSE did not explain the lack of association between the dose of nutrition support during the first 6 days of ENS and 28day mortality. 
Table 1 Characteristics of the enrolled patients

\begin{tabular}{|c|c|c|c|c|c|c|c|}
\hline $\begin{array}{l}\text { Patient } \\
\text { characteristics }\end{array}$ & $\begin{array}{l}\text { Enrolled patients } \\
(n=440)\end{array}$ & $\begin{array}{l}\text { Survivors } \\
(n=317)\end{array}$ & $\begin{array}{l}\text { Nonsurvivors } \\
(n=123)\end{array}$ & $p$ value & $\begin{array}{l}\text { Short-term ENS } \\
\text { ( } \leq 6 \text { days) }(n=106)\end{array}$ & $\begin{array}{l}\text { Longer-term ENS } \\
(\geq 7 \text { days) }(n=146)\end{array}$ & $p$ value \\
\hline Age (years) & $61.4(15.7)$ & $59.3(15.9)$ & $66.8(14.1)$ & $<0.001$ & $60.4(16.9)$ & $59.5(15.5)$ & 0.655 \\
\hline Male & $259[58.9]$ & $192[60.6]$ & $67[54.5]$ & 0.244 & $63[59.4]$ & $92[63.0]$ & 0.564 \\
\hline BMI $\left(\mathrm{kg} / \mathrm{m}^{2}\right)$ & $24.4[21.3,28.2]$ & $24.4[21.2,28.0]$ & $24.2[21.3,28.6]$ & 0.955 & $24.5[21.2,29.5]$ & $24.6[21.8,28.4]$ & 0.726 \\
\hline Location before adm. & & & & 0.003 & & & 0.976 \\
\hline $\mathrm{ED} / \mathrm{HD} / \mathrm{OT}$ & 357 [81.1] & $268[84.5]$ & $89[72.4]$ & & $88[83.0]$ & $121[82.9]$ & \\
\hline Wards & 83 [18.9] & $49[15.5]$ & $34[27.6]$ & & $18[17.0]$ & $25[17.1]$ & \\
\hline Type of adm. & & & & 0.006 & & & 0.001 \\
\hline Medical & $293[66.6]$ & 199 [62.8] & $94[76.4]$ & & 80 [75.5] & $79[54.1]$ & \\
\hline Surgery & $147[33.4]$ & 118 [37.2] & 29 [23.6] & & $26[24.5]$ & $67[45.9]$ & \\
\hline Number of comorbidities & $2.0[1.0,4.0]$ & $2.0[1.0,4.0]$ & $3.0[2.0,4.0]$ & 0.069 & $3.0[1.0,4.0]$ & $2.0[1.0,3.0]$ & 0.002 \\
\hline LOS before ICU adm. (days) & $0.0[0.0,1.0]$ & $0.0[0.0,1.0]$ & $1.0[0.0,3.0]$ & 0.009 & $0.0[0.0,1.3]$ & $0.0[0.0,1.3]$ & 0.730 \\
\hline APACHE ॥ & $24.5(8.1)$ & $22.6(7.4)$ & $29.5(7.7)$ & $<0.001$ & $25.4(8.4)$ & $24.7(7.6)$ & 0.543 \\
\hline SOFA & $8.7(3.8)$ & $7.9(3.5)$ & $10.7(3.8)$ & $<0.001$ & $9.2(3.7)$ & $9.1(3.8)$ & 0.909 \\
\hline mNUTRIC & $5.3(2.1)$ & $4.8(2.1)$ & $6.6(1.5)$ & $<0.001$ & $5.5(2.3)$ & $5.3(2.0)$ & 0.531 \\
\hline mNUTRIC $\geq 5$ & 299 [68.0] & $187[59.0]$ & 112 [91.1] & $<0.001$ & $74[69.8]$ & $100[68.5]$ & 0.823 \\
\hline Malnutrition & 123 [28.0] & 72 [22.7] & $51[41.5]$ & $<0.001$ & $31[29.2]$ & 35 [24.0] & 0.347 \\
\hline Admission reasons & & & & $<0.001$ & & & 0.020 \\
\hline Cardiovascular & 82 [18.6] & $43[13.6]$ & 39 [31.7] & & 19 [17.9] & 18 [12.3] & \\
\hline Respiratory & 84 [19.1] & $68[21.5]$ & $16[13.0]$ & & $24[22.6]$ & $21[14.4]$ & \\
\hline Sepsis & 105 [23.9] & $72[22.7]$ & $33[26.8]$ & & $36[34.0]$ & $39[26.7]$ & \\
\hline Trauma & $12[2.7]$ & $12[3.8]$ & $0[0.0]$ & & $4[3.3]$ & $4[2.7]$ & \\
\hline Metabolic/renal & $8[1.8]$ & $8[2.5]$ & $0[0.0]$ & & $2[1.9]$ & $2[1.4]$ & \\
\hline Gastrointestinal & $42[9.6]$ & $29[9.2]$ & 13 [10.6] & & $3[2.8]$ & $8[5.5]$ & \\
\hline Postoperation & $13[3.0]$ & $12[3.8]$ & $1[0.8]$ & & $4[3.8]$ & $3[2.1]$ & \\
\hline Orthopaedics & $7[1.6]$ & $6[1.9]$ & $1[0.8]$ & & $1[0.9]$ & $2[1.4]$ & \\
\hline Neurological & 87 [19.8] & $67[21.1]$ & 20 [16.3] & & 13 [12.3] & $49[33.6]$ & \\
\hline CPR before ICU adm. & $53[12.1]$ & $17[5.4]$ & $36[29.3]$ & $<0.001$ & $18[17.0]$ & 18 [12.3] & 0.297 \\
\hline Length of MV (days) & $2.0[1.0,5.0]$ & $2.0[1.0,4.0]$ & $3.0[2.0,6.0]$ & $<0.001$ & $3.0[2.0,4.0]$ & $7.0[4.0,13.0]$ & $<0.001$ \\
\hline ICU LOS (days) & $2.0[2.0,5.0]$ & $2.0[1.0,4.0]$ & $3.0[2.0,6.0]$ & 0.001 & $3.0[2.0,4.0]$ & $7.0[4.0,12.0]$ & $<0.001$ \\
\hline Hospital LOS (days) & $14.0[7.0,25.0]$ & $15.0[9.0,33.0]$ & $9.0[4.0,16.0]$ & $<0.001$ & $8.0[4.0,15.3]$ & $24.0[16.0,45.0]$ & $<0.001$ \\
\hline
\end{tabular}

Values are mean (standard deviation), median [Q1, Q3], or count [percentage]

$A d m$. admission, $A P A C H E$ II Acute Physiology and Chronic Health Evaluation II, BMI body mass index, CPR cardiopulmonary resuscitation, ED emergency department, ENS exclusive nutritional support, HD high dependency, ICU intensive care unit, LOS length of stay, MV mechanical ventilation, mNUTRIC Modified Nutrition Risk in Critically III, OT operation theatre, SOFA Sequential Organ Failure Assessment

\section{Prognostic performance}

The GLIMPSE model can be viewed as an extension of the mNUTRIC score. The latter had a $C$-index and maxrescaled $R^{2}$ of 0.65 and 0.57 , respectively [2]. However, subsequent large multicentre cohort studies $(n>1000)$ that sought to validate mNUTRIC demonstrated reduced prognostic performance, with the $C$-index and max-rescaled $R^{2}$ ranging from 0.65 to 0.7 and from 0.09 to 0.16 , respectively $[6,15]$. In our study, the GLIMPSE model demonstrated better prognostic performance than that of the mNUTRIC. This may be attributed to the inclusion of strong independent predictors of mortality (nutritional status and CPR) [4]. Despite its good prognostic performance, the GLIMPSE model was unable to explain the lack of association between early high energy and protein intakes and 28-day mortality.

\section{Validity of GLIMPSE as an assessment tool for nutritional support}

The prevalence of malnutrition in the ICU reportedly ranges from 28 to $78 \%$ [4]. Urgent nutritional support, which often translates to early high energy and protein 
Table 2 Comparison of goal and achieved energy and protein intakes between 28-day survivors and nonsurvivors stratified by days of exclusive nutritional support

\begin{tabular}{|c|c|c|c|c|}
\hline Nutritional parameters & All patients & Survivors & Nonsurvivors & $p$ value \\
\hline \multicolumn{5}{|c|}{ Short-term exclusive nutritional support ( $\leq 6$ days) } \\
\hline \multicolumn{5}{|l|}{ Energy } \\
\hline Goal (kcal/kg) & $25.7(5.8)$ & $25.5(5.5)$ & $25.9(6.3)$ & 0.680 \\
\hline Actual intake (kcal/kg) & $12.0(6.6)$ & $10.0(6.0)$ & $15.0(6.4)$ & $<0.001$ \\
\hline Actual intake (\% goal/kg) & $48.0(24.9)$ & $40.0(22.4)$ & $59.2(24.1)$ & $<0.001$ \\
\hline \multicolumn{5}{|l|}{ Protein } \\
\hline Goal (g/kg) & $1.14(0.23)$ & $1.14(0.20)$ & $1.15(0.26)$ & 0.779 \\
\hline Actual intake (g/kg) & $0.47(0.29)$ & $0.39(0.26)$ & $0.57(0.30)$ & 0.001 \\
\hline Actual intake (\% goal/kg) & $41.6(25.0)$ & $34.7(21.6)$ & $51.4(26.4)$ & 0.001 \\
\hline \multicolumn{5}{|c|}{ Longer-term exclusive nutritional support ( $\geq 7$ days) } \\
\hline \multicolumn{5}{|l|}{ Energy } \\
\hline Goal (kcal/kg) & $25.6(4.4)$ & $25.9(4.4)$ & $24.8(4.3)$ & 0.166 \\
\hline Actual intake (kcal/kg) & $17.5(5.3)$ & $17.7(5.2)$ & $16.9(5.7)$ & 0.389 \\
\hline Actual intake (\% goal/kg) & $68.7(18.2)$ & $68.8(17.8)$ & $68.2(19.5)$ & 0.857 \\
\hline \multicolumn{5}{|l|}{ Protein } \\
\hline Goal (g/kg) & $1.19(0.22)$ & $1.20(0.21)$ & $1.15(0.26)$ & 0.281 \\
\hline Actual intake (g/kg) & $0.77(0.25)$ & $0.79(0.24)$ & $0.71(0.28)$ & 0.125 \\
\hline Actual intake (\% goal/kg) & $64.8(19.1)$ & $66.1(18.9)$ & $61.6(19.4)$ & 0.206 \\
\hline
\end{tabular}

intakes, is recommended for malnourished critically ill patients because it confers clinical benefits $[16,17]$. To our knowledge, this has not been examined in randomized controlled trials performed in ICUs because this subgroup of patients is often excluded for ethical reasons. When examined in the subgroup or post hoc analyses, patients at risk of malnutrition did not benefit from higher energy and protein intakes [18, 19]. Given the paucity of evidence, our prospective observational study may help in bridging this knowledge gap, i.e.

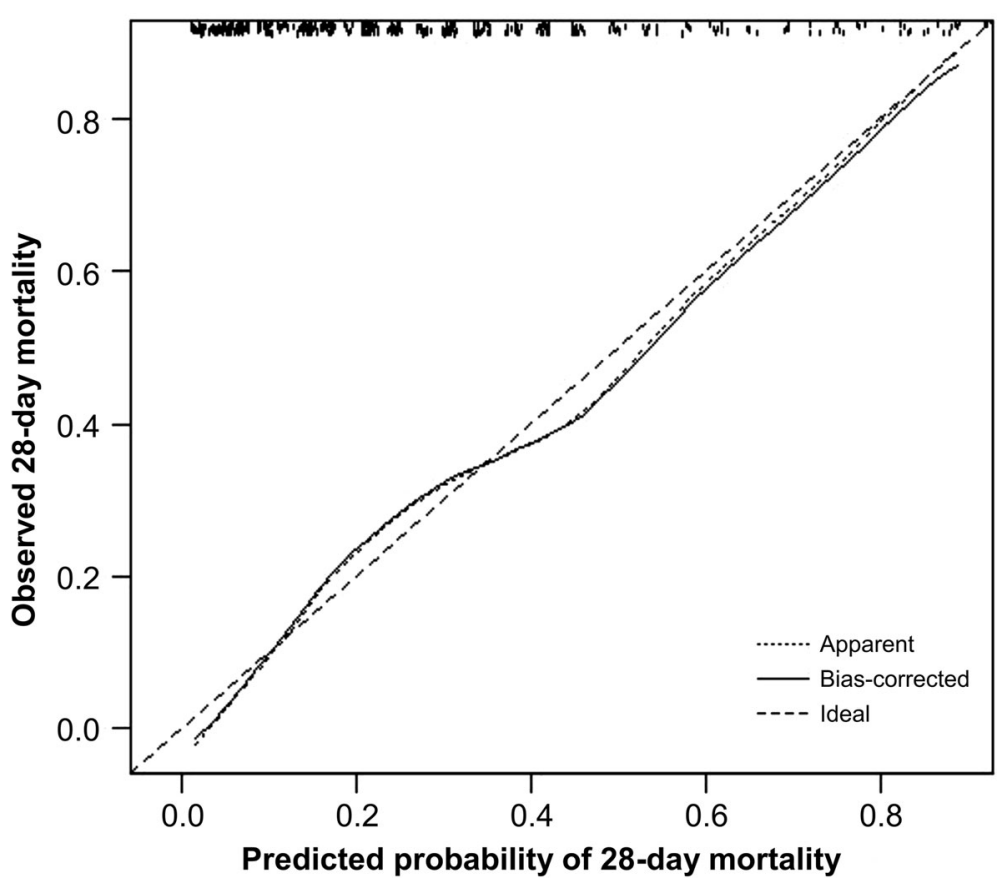

Fig. 2 Bias-corrected calibration curve for the prediction of 28-day mortality 
Table 3 Characteristics of low- and high-GLIMPSE patients

\begin{tabular}{|c|c|c|c|}
\hline Patient characteristics & Low-GLIMPSE $(n=188)$ & High-GLIMPSE $(n=252)$ & $p$ value \\
\hline Age (years) & $53.6(16.0)$ & $67.2(12.8)$ & $<0.001$ \\
\hline Male & $115[61.2]$ & $144[57.1]$ & 0.396 \\
\hline BMI $\left(\mathrm{kg} / \mathrm{m}^{2}\right)$ & $25.5(6.3)$ & $24.9(5.8)$ & 0.262 \\
\hline Location before adm. & & & $<0.001$ \\
\hline $\mathrm{ED} / \mathrm{HD} / \mathrm{OT}$ & 169 [89.9] & $188[74.6]$ & \\
\hline Wards & $19[10.1]$ & $64[25.4]$ & \\
\hline Type of adm. & & & $<0.001$ \\
\hline Medical & $104[55.3]$ & $189[75.0]$ & \\
\hline Surgery & $84[44.7]$ & $63[25.0]$ & \\
\hline Number of comorbidities & $2.0[1.0,3.0]$ & $3.0[2.0,4.0]$ & $<0.001$ \\
\hline LOS before ICU adm. (days) & $0.0[0.0 .1 .0]$ & $1.0[0.0,2.5]$ & $<0.001$ \\
\hline APACHE ॥ & $18.6(5.2)$ & $29.0(6.9)$ & $<0.001$ \\
\hline SOFA & $6.4(3.0)$ & $10.3(3.4)$ & $<0.001$ \\
\hline mNUTRIC & $3.4(1.5)$ & $6.7(1.2)$ & $<0.001$ \\
\hline mNUTRIC $\geq 5$ (high-mNUTRIC) & $55[29.3]$ & $244[96.8]$ & $<0.001$ \\
\hline Malnutrition & $29[15.4]$ & $94[37.3]$ & $<0.001$ \\
\hline Predicted mortality risk & $9.7(5.0)$ & $41.6(19.5)$ & $<0.001$ \\
\hline Admission reasons & & & $<0.001$ \\
\hline Cardiovascular & $22[11.7]$ & $60[23.8]$ & \\
\hline Respiratory & 39 [20.7] & $45[17.9]$ & \\
\hline Sepsis & $26[13.8]$ & $79[31.4]$ & \\
\hline Trauma & $11[5.9]$ & $1[0.4]$ & \\
\hline Metabolic/renal & $3[1.6]$ & $5[2.0]$ & \\
\hline Gastrointestinal & $15[8.0]$ & 27 [10.7] & \\
\hline Postoperation & $9[4.8]$ & $4[1.6]$ & \\
\hline Orthopaedics & $3[1.6]$ & $4[1.6]$ & \\
\hline Neurological & $60[31.9]$ & 27 [10.7] & \\
\hline CPR before ICU adm. & $1[0.5]$ & $52[20.6]$ & $<0.001$ \\
\hline Length of MV (days) & $2.0[1.0,4.0]$ & $2.0[1.0,5.0]$ & 0.039 \\
\hline ICU LOS (days) & $2.0[2.0,5.0]$ & $3.0[2.0,5.0]$ & 0.381 \\
\hline Hospital LOS (days) & $13.5[7.0,27.0]$ & $14.0[7.0,24.0]$ & 0.953 \\
\hline
\end{tabular}

Values are mean (standard deviation), median [Q1, Q3], or count [percentage]

Adm. admission, APACHE II Acute Physiology and Chronic Health Evaluation II, BMI body mass index, CPR cardiopulmonary resuscitation, ED emergency

department, ENS exclusive nutritional support, HD high dependency, ICU intensive care unit, LOS length of stay, MV mechanical ventilation, mNUTRIC Modified

Nutrition Risk in Critically III, OT operation theatre, SOFA Sequential Organ Failure Assessment

whether the associations between the dose of energy and protein intakes and mortality risk could be modified by the baseline nutritional status of critically ill patients.

The GLIMPSE tool was developed because it was hypothesized that baseline nutritional status and disease severity could modify the association between the dose of energy and protein intakes and mortality risk. However, this was not supported by the data in the current study. The disparity between early high energy and protein intakes and 28-day mortality in patients with short- and longerterm ENS was unexpected, as was the lack of discrimination by the integration of nutritional status with disease severity in the GLIMPSE model. Further stratification of nutritional status in these two groups of patients also revealed that the associations between energy and protein intakes and 28-day mortality were independent of baseline nutritional status (Table 4). The only overt differences between patients with short- and longer-term ENS were their exposure to surgery and the type of admission diagnosis, with patients who had short-term ENS being more likely to be admitted for medical reasons and having a higher incidence of cardiovascular or respiratory issues. In contrast, a higher proportion of patients with longer-term ENS were admitted with neurological diagnoses (Table 1). 
Table 4 Association between energy and protein intakes and 28-day mortality as well as nutritional status stratified by days on exclusive nutritional support and GLIMPSE groups

\begin{tabular}{|c|c|c|c|c|c|c|}
\hline \multirow[t]{2}{*}{ Parameters } & \multicolumn{2}{|c|}{ Short-term ENS ( $\leq 6$ days) } & \multicolumn{2}{|c|}{ Longer-term ENS ( $\geq 7$ days) } & \multirow[t]{2}{*}{$p$ value } & \\
\hline & Low-GLIMPSE* $(n=36)$ & High-GLIMPSE* $(n=70)$ & Low-GLIMPSE* $(n=64)$ & High-GLIMPSE $^{*}(n=82)$ & & \\
\hline Energy intake & & & & & $0.793^{\dagger}$ & $0.035^{\ddagger}$ \\
\hline \multirow[t]{3}{*}{ Each $10 \%$ of goal } & $1.24(0.70-2.20)$ & $1.60(1.19-2.15)$ & $2.17(0.75-6.26)$ & $0.83(0.64-1.12)$ & & \\
\hline & $p=0.462$ & $p=0.002$ & $p=0.150$ & $p=0.228$ & & \\
\hline & $\mathrm{GOF}=0.682$ & $\mathrm{GOF}=0.823$ & $\mathrm{GOF}=0.287$ & $\mathrm{GOF}=0.615$ & & \\
\hline Protein intake & & & & & $0.904^{\S}$ & $0.025^{* *}$ \\
\hline \multirow[t]{3}{*}{ Each $10 \%$ of goal } & $1.20(0.68-2.11)$ & $1.47(1.12-1.86)$ & $1.23(0.73-2.08)$ & $0.75(0.57-0.99)$ & & \\
\hline & $p=0.535$ & $p=0.004$ & $p=0.428$ & $p=0.043$ & & \\
\hline & $\mathrm{GOF}=0.685$ & $\mathrm{GOF}=0.530$ & $\mathrm{GOF}=0.455$ & $\mathrm{GOF}=0.335$ & & \\
\hline 7-point SGA-categories & & & & & $0.480^{\dagger \dagger}$ & $0.633^{\text {丰 }}$ \\
\hline \multicolumn{7}{|l|}{ Well-nourished } \\
\hline SGA-7 & $22[61.1]$ & $34[48.6]$ & $41[64.1]$ & $34[41.5]$ & & \\
\hline SGA-6 & $8[22.2]$ & $11[15.7]$ & $18[28.1]$ & 18 [22.0] & & \\
\hline \multicolumn{7}{|c|}{ Mildly to moderately malnourished } \\
\hline SGA-5 & $3[8.3]$ & $8[11.4]$ & $4[6.3]$ & 14 [17.1] & & \\
\hline$S G A-4$ & $2[5.6]$ & $7[10.0]$ & $1[1.6]$ & $9[11.0]$ & & \\
\hline SGA-3 & $1[2.8]$ & $5[7.1]$ & $0[0.0]$ & $5[6.1]$ & & \\
\hline \multicolumn{7}{|l|}{ Severely malnourished } \\
\hline SGA-2 & & $4[5.7]$ & & $2[2.4]$ & & \\
\hline SGA-1 & & 1 [1.4] & & $0[0.0]$ & & \\
\hline
\end{tabular}

Values are adjusted odds ratio (95\% confidence interval) adjusted for days on exclusive nutritional support and count [percentage]. Refer to Additional file 1 for beta weights of potential confounders not included in the model

ENS exclusive nutritional support, GLIMPSE Global Index of Mortality Probability in the Severely ill, GOF goodness of fit derived from Hosmer-Lemeshow test, SGA Subjective Global Assessment

*Low- and high-GLIMPSE is defined as the predicted mortality risk of $<20 \%$ and $>20 \%$, respectively

${ }^{\dagger}$ Interaction between energy intake and GLIMPSE categories in patients with short-term exclusive nutritional support

${ }^{\ddagger}$ Interaction between energy intake and GLIMPSE categories in patients with longer-term exclusive nutritional support

\$Interaction between protein intake and GLIMPSE categories in patients with shorter-term exclusive nutritional support

**Interaction between protein intake and GLIMPSE categories in patients with longer-term exclusive nutritional support

${ }^{+\dagger}$ Comparison of 7-point SGA categories between low-GLIMPSE patients with short-term and longer-term ENS

${ }^{\ddagger \ddagger}$ Comparison of 7-point SGA categories between high-GLIMPSE patients with short-term and longer-term ENS

One of the possible explanations for the results of our study could be the metabolic state (i.e. catabolism vs. anabolism) at the initial phase of nutritional support, since this will dictate the fate of exogenous macronutrient metabolism. Catabolism-During the acute phase of critical illness, raised concentrations of glucagon, catecholamines, and cortisol may result in anabolic resistance [20]. Therefore, energy and protein provided at this stage may not be effectively used for anabolism or attenuation of catabolism (processes required to treat malnutrition) [21-23]. This has been reported in recent studies, where early high protein intake during the acute phase of critical illness led to increased ureagenesis (reflecting inefficiency in protein metabolism [24-27]). Furthermore, early high energy and protein intakes were associated with poorer clinical outcomes, such as prolonged ICU length of stay and increased risk of infection [18] as well as a greater degree of muscle and functional loss [22, 28, 29]. Mechanistically, these results may be attributed to hindered autophagy [28, 30], attenuation of the nonthyroidal illness syndrome [31] or intramuscular inflammation, and altered hypoxic signalling, which consequently reduces the bioavailability of the intramuscular adenosine triphosphate needed for muscle protein synthesis [29]. Anabolism-By contrast, during the later phase of critical illness, inflammation and the levels of hormones responsible for catabolism gradually abate; this may result in more efficient use of energy and protein for anabolism and recovery [32].

The number, type, and degree of insults for each critically ill patient differ widely in the ICU. Therefore, some patients will be in a prolonged catabolic state, whereas others progress quickly into the anabolic phase (the later stage of a critical illness) [32]. From the literature, it may be deduced that the acute state can be as short as 3 days [33] or as long as 7 days [34-36]. In the acute state, high energy and protein intakes have been shown to worsen clinical outcomes, whereas the same nutrient delivery at 
the later stage has shown to have clinical benefits [33-36]. Variability in the duration of the acute state could explain the different effects of early high energy and protein intakes in our study. That is, the positive association between energy and protein intakes and 28-day mortality in high-GLIMPSE patients with short-term ENS may reflect the consequence of early high energy and protein intakes in an overt state of catabolism, whereas the negative association in patients with longer-term ENS suggests an early resolution of catabolism, and hence, energy and protein could be efficiently used for anabolism. This hypothesis could also explain why Compher et al. [6] observed an inverse association between the dose of nutrition support and mortality in patients with $>4$ days of ENS - an observation congruent with patients with longer-term ENS ( $\geq 7$ days) in our study. The inclusion criteria used by Compher et al. [6] could inherently have selected patients who were somewhat in the anabolic phase and hence benefited from higher energy and protein intakes. Therefore, their findings [6] may only apply to patients with $>4$ days of ENS, and the extrapolation of these results to recommend early aggressive nutritional support to all severely ill ICU patients may require caution.

The current study had a number of strengths. These include consecutive recruitment and complete followup, which minimised the selection and attrition biases. In addition, we avoided an erroneous association between minimal nutritional intake and mortality by excluding moribund patients, since these patients inherently have a minimal nutritional intake, and death reflects disease severity. However, there were several limitations. First, although GLIMPSE was found to have good mortality prognostic performance, it was unable to characterize the dynamic disease progression of critically ill patients. For example, patients admitted with diabetic ketoacidosis and severe pancreatitis may have identical GLIMPSE scores, but the former would have a rapid metabolic recovery, whereas the insult suffered by the latter may worsen. Since GLIMPSE, along with other prognostic scores, such as the mNUTRIC, are measured once at day 2 of ICU admission, they are unable to account for the differing pathophysiologies and disease progressions under different conditions. Therefore, future studies should collect covariates such as levels of organ support and sequential SOFA score to adjust for these time-dependent parameters. Second, the prognostic accuracies of GLIMPSE were based on a single centre with relatively small sample size, and larger multi-site studies are required to more accurately estimate the prognostic performance of the GLIMPSE model. Third, as in all observational studies, the possibility of residual confounding factors limited the interpretation of the results in this study to the association rather than to the causality. Lastly, nutritional status was not reassessed during the course of ICU admission. Therefore, some patients who were well-nourished at baseline may have become malnourished during their stay in the ICU.

\section{Future research and clinical implications}

As the fate of nutrient metabolism during the acute and later phases of critical illness is different, it is crucial for future studies to identify the biomarkers that can accurately define the duration of the different phases to better guide nutritional support in the ICU [32]. Before this is achieved, perhaps the timing and dose of energy and protein intakes should be guided by the surrogates of inflammation resolution, e.g. down-trending of high-sensitivity C-reactive protein, reduced insulin resistance (improved glycaemic control in patients without diabetes [37]), or improvement in organ functions (down-trending of the sequential SOFA scores) [38] and levels of transthyretin [39]. In addition, emerging evidence [10, 33, 34, 38, 39] and recent guidelines [40] are supportive of progressive provision of energy and protein during the first week of ICU admission.

\section{Conclusions}

By integrating the predictors such as baseline nutritional status and disease severity, the GLIMPSE model demonstrated good prognostic performance in the prediction of 28-day mortality in critically ill patients. However, these predictors did not modify the association between the dose of nutrition support during the first 6 days of ENS and 28-day mortality. This suggests that the mortality-modifying effects of nutritional support are independent of the baseline nutritional status and disease severity of critically ill patients.

\section{Additional file}

Additional file 1: Supplementary data. (DOCX $14 \mathrm{~kb}$ )

\section{Abbreviations}

APACHE II: Acute Physiology and Chronic Health Evaluation II; ENS: Exclusive nutritional support; GLIMPSE: Global Index of Mortality Probability in the Severely ill; ICU: Intensive care unit; mNUTRIC: Modified Nutrition Risk in Critically III score; SGA: Subjective Global Assessment; SOFA: Sequential Organ Failure Assessment

\section{Acknowledgements}

We are grateful for the statistical support provided by Wong Chiew Meng Johnny, Biostatistician (MSc Medical Statistics, London School of Hygiene \& Tropical Medicine), Clinical Research Unit, JurongHealth Campus.

\section{Authors' contributions}

All authors equally contributed to the conception and design of the research. CCHL, GJYW, and KPC contributed to the acquisition of the data. $\mathrm{CCHL}$ contributed to the analysis and interpretation of the data and drafted the manuscript. All authors critically revised the manuscript, agree to be fully 
accountable for ensuring the integrity and accuracy of the work, and have read and approved the final manuscript.

\section{Funding}

The study was funded by the JurongHealth Internal Research \& Development (R\&D) Grant. The sponsor of the study had no role in the design of the study; collection, analysis, and interpretation of the data; and in the writing of the manuscript.

\section{Availability of data and materials}

The datasets generated and/or analysed during the current study are not publicly available due to the data confidentiality requirements of the ethics committee; however, they are available from the corresponding author on reasonable request and approval from the ethics committee.

\section{Ethics approval and consent to participate}

Ethics approval was granted by the Domain Specific Review Board (NHG DSRB Ref: 2014/00878), and informed consent was not required since this was an observational study where no attempt was made to change the standard of care.

\section{Consent for publication}

$$
\text { Not applicable }
$$

\section{Competing interests}

The authors declare that they have no competing interests.

\section{Author details}

${ }^{1}$ Nutrition and Dietetics, College of Nursing and Health Sciences, Flinders University, GPO Box 2100, Adelaide 5001, South Australia. ${ }^{2}$ Dietetics and Nutrition Department, Ng Teng Fong General Hospital, 1 Jurong East Street 21, Singapore 609606, Singapore. ${ }^{3}$ Department of Gastroenterology and Hepatology, College of Medicine and Public Health, Flinders University, GPO Box 2100, Adelaide 5001, South Australia. ${ }^{4}$ Department of Respiratory Medicine, Ng Teng Fong General Hospital, 1 Jurong East Street 21, Singapore 609606, Singapore. ${ }^{5}$ Saw Swee Hock School of Public Health, National University of Singapore, 12 Science Drive 2, \#10-01, Singapore 117549, Singapore.

\section{Received: 28 February 2019 Accepted: 29 May 2019}

\section{Published online: 18 June 2019}

\section{References}

1. Heyland DK, Dhaliwal R, Jiang X, Day AG. Identifying critically ill patients who benefit the most from nutrition therapy: the development and initial validation of a novel risk assessment tool. Crit Care. 2011;15:1.

2. Rahman A, Hasan RM, Agarwala R, Martin C, Day AG, Heyland DK. Identifying critically-ill patients who will benefit most from nutritional therapy: further validation of the "modified NUTRIC" nutritional risk assessment tool. Clin Nutr. 2016;35:158-62

3. Lew CCH, Cheung KP, Chong MFF, Chua AP, Fraser RJL, Miller M. Combining 2 commonly adopted nutrition instruments in the critical care setting is superior to administering either one alone. JPEN J Parenter Enteral Nutr. 2018:42:872-6

4. Lew CCH, Wong GJY, Cheung KP, Chua AP, Chong MFF, Miller M Association between malnutrition and 28-day mortality and intensive care length-of-stay in the critically ill: a prospective cohort study. Nutrients. 2017;10:10.

5. Lew CCH, Yandell R, Fraser RJ, Chua AP, Chong MFF, Miller M. Association between malnutrition and clinical outcomes in the intensive care unit: a systematic review. JPEN J Parenter Enteral Nutr. 2017:41:744-58.

6. Compher C, Chittams J, Sammarco T, Nicolo M, Heyland DK. Greater protein and energy intake may be associated with improved mortality in higher risk critically ill patients: a multicenter, multinational observational study. Crit Care Med. 2017:45:156-63.

7. Mukhopadhyay A, Henry J, Ong V, Leong CS, Teh AL, van Dam RM, et al. Association of modified NUTRIC score with 28-day mortality in critically ill patients. Clin Nutr. 2017;36:1143-8.

8. Arabi YM, Tamim HM, Sadat M. Reply to Compher et al:. reservations about permissive underfeeding in low versus high NUTRIC patients? Am J Respir Crit Care Med. 2018;197:1228-9.
9. Lee ZY, Noor Airini I, Barakatun-Nisak MY. Relationship of energy and protein adequacy with 60-day mortality in mechanically ventilated critically ill patients: a prospective observational study. Clin Nutr. 2018;37:1264-70.

10. Lew CCH, Wong GJY, Cheung KP, Fraser RJ, Chua AP, Chong MFF, et al. When timing and dose of nutrition support were examined, the modified Nutrition Risk in Critically III (mNUTRIC) score did not differentiate high-risk patients who would derive the most benefit from nutrition support: a prospective cohort study. Ann Intensive Care. 2018;8:98.

11. Lee $Z Y$, Heyland DK. Determination of nutrition risk and status in critically ill patients: what are our considerations? Nutr Clin Pract. 2019;34(1):96-111.

12. Green SB. How many subjects does it take to do a regression analysis. Multivariate Behav Res. 1991;26:499-510.

13. Bewick V, Cheek L, Ball J. Statistics review 13: receiver operating characteristic curves. Crit Care. 2004;8:508-12.

14. Heyland DK, Cahill N, Day AG. Optimal amount of calories for critically ill patients: depends on how you slice the cake! Crit Care Med. 2011;39:2619-26.

15. Mendes R, Policarpo S, Fortuna P, Alves M, Virella D, Heyland DK, et al. Nutritional risk assessment and cultural validation of the modified NUTRIC score in critically ill patients - a multicenter prospective cohort study. J Crit Care. 2017:37:45-9.

16. Kreymann KG, Berger MM, Deutz NE, Hiesmayr M, Jolliet P, Kazandjiev G, et al. ESPEN guidelines on enteral nutrition: intensive care. Clin Nutr. 2006; 25:210-23.

17. McClave SA, Taylor BE, Martindale RG, Warren MM, Johnson DR, Braunschweig C, et al. Guidelines for the provision and assessment of nutrition support therapy in the adult critically ill patient: Society of Critica Care Medicine (SCCM) and American Society for Parenteral and Enteral Nutrition (ASPEN). JPEN J Parenter Enteral Nutr. 2016:40:159-211.

18. Casaer MP, Mesotten D, Hermans G, Wouters PJ, Schetz M, Meyfroidt G, et al. Early versus late parenteral nutrition in critically ill adults. N Engl J Med. 2011;365:506-17

19. Fivez T, Kerklaan D, Mesotten D, Verbruggen S, Wouters PJ, Vanhorebeek I, et al. Early versus late parenteral nutrition in critically ill children. N Engl J Med. 2016:374:1111-22.

20. Thiessen SE, Gunst J, Van den Berghe G. Role of glucagon in protein catabolism. Curr Opin Crit Care. 2018;24:228-34.

21. Plank LD, Connolly AB, Hill GL. Sequential changes in the metabolic response in severely septic patients during the first 23 days after the onset of peritonitis. Ann Surg. 1998;228:146-58.

22. Puthucheary ZA, Rawal J, McPhail M, Connolly B, Ratnayake G, Chan P, et al. Acute skeletal muscle wasting in critical illness. JAMA. 2013;310:1591-600.

23. Tappy L, Berger M, Schwarz JM, McCamish M, Revelly JP, Schneiter P, et al. Hepatic and peripheral glucose metabolism in intensive care patients receiving continuous high- or low-carbohydrate enteral nutrition. JPEN J Parenter Enteral Nutr. 1999:23:260-7 discussion 7-8.

24. Allingstrup MJ, Kondrup J, Wiis J, Claudius C, Pedersen UG, Hein-Rasmussen $\mathrm{R}$, et al. Early goal-directed nutrition versus standard of care in adult intensive care patients: the single-centre, randomised, outcome assessorblinded EAT-ICU trial. Intensive Care Med. 2017:43:1637-47.

25. Doig GS, Simpson F, Bellomo R, Heighes PT, Sweetman EA, Chesher D, et al. Intravenous amino acid therapy for kidney function in critically ill patients: a randomized controlled trial. Intensive Care Med. 2015:41:1197-208.

26. Gunst J, Vanhorebeek I, Casaer MP, Hermans G, Wouters PJ, Dubois J, et al. Impact of early parenteral nutrition on metabolism and kidney injury. J Am Soc Nephrol. 2013:24:995-1005.

27. Vanhorebeek I, Verbruggen S, Casaer MP, Gunst J, Wouters PJ, Hanot J, et al. Effect of early supplemental parenteral nutrition in the paediatric ICU: a preplanned observational study of post-randomisation treatments in the PEPaNIC trial. Lancet Respir Med. 2017;5:475-83.

28. Hermans G, Casaer MP, Clerckx B, Guiza F, Vanhullebusch T, Derde S, et al. Effect of tolerating macronutrient deficit on the development of intensivecare unit acquired weakness: a subanalysis of the EPaNIC trial. Lancet Respir Med. 2013;1:621-9.

29. Puthucheary ZA, Astin R, McPhail MJW, Saeed S, Pasha Y, Bear DE, et al. Metabolic phenotype of skeletal muscle in early critical illness. Thorax. 2018; 73:926-35.

30. Van Dyck L, Casaer MP, Gunst J. Autophagy and its implications against early full nutrition support in critical illness. Nutr Clin Pract. 2018;33:339-47.

31. McKeever L, Bonini M, Braunschweig C. Feeding during phases of altered mitochondrial activity: a theory. JPEN J Parenter Enteral Nutr. 2018:42:855-63. 
32. Arabi YM, Al-Dorzi HM. Trophic or full nutritional support? Curr Opin Crit Care. 2018;24:262-8.

33. Koekkoek W, van Setten CHC, Olthof LE, Kars J, van Zanten ARH. Timing of protein intake and clinical outcomes of adult critically ill patients on prolonged mechanical ventilation: the PROTINVENT retrospective study. Clin Nutr. 2019;38(2):883-90.

34. Braunschweig CL, Freels S, Sheean PM, Peterson SJ, Perez SG, McKeever L, et al. Role of timing and dose of energy received in patients with acute lung injury on mortality in the Intensive Nutrition in Acute Lung Injury Trial (INTACT): a post hoc analysis. Am J Clin Nutr. 2017;105:411-6.

35. Peterson SJ, Lateef OB, Freels S, McKeever L, Fantuzzi G, Braunschweig CA. Early exposure to recommended calorie delivery in the intensive care unit is associated with increased mortality in patients with acute respiratory distress syndrome. JPEN J Parenter Enteral Nutr 2017:148607117713483.

36. Casaer MP, Wilmer A, Hermans G, Wouters PJ, Mesotten D, van den Berghe G. Role of disease and macronutrient dose in the randomized controlled EPaNIC trial: a post hoc analysis. Am J Respir Crit Care Med. 2013;187:247-55.

37. Casaer MP, Reignier J, Doig G. Optimal guidance for early nutrition therapy in critical illness? Intensive Care Med. 2017:43:1720-2.

38. Peterson SJ, McKeever L, Lateef OB, Freels S, Fantuzzi G, Braunschweig CA. Combination of high-calorie delivery and organ failure increases mortality among patients with acute respiratory distress syndrome. Crit Care Med. 2019;47:69-75

39. Berger MM, Pantet O, Jacquelin-Ravel N, Charriere M, Schmidt S, Becce F, et al. Supplemental parenteral nutrition improves immunity with unchanged carbohydrate and protein metabolism in critically ill patients: the SPN2 randomized tracer study. Clin Nutr. 2018. [Epub ahead of print]. https://doi.org/10.1016/j.clnu.2018.10.023.

40. Singer P, Blaser AR, Berger MM, et al. ESPEN guideline on clinical nutrition in the intensive care unit. Clin Nutr. 2019;38(1):48-79.

\section{Publisher's Note}

Springer Nature remains neutral with regard to jurisdictional claims in published maps and institutional affiliations.

Ready to submit your research? Choose BMC and benefit from:

- fast, convenient online submission

- thorough peer review by experienced researchers in your field

- rapid publication on acceptance

- support for research data, including large and complex data types

- gold Open Access which fosters wider collaboration and increased citations

- maximum visibility for your research: over $100 \mathrm{M}$ website views per year

At $\mathrm{BMC}$, research is always in progress.

Learn more biomedcentral.com/submissions 